\title{
Leadership Institute for Faculty Development
}

\author{
Douglas J. Gould ${ }^{1}$ (D) Michelle Hammond ${ }^{2}$
}

Accepted: 23 November 2020 / Published online: 20 January 2021

(C) International Association of Medical Science Educators 2021

\begin{abstract}
The purpose of the present project is to describe a cohort-based intradepartmental leadership program at our medical school. Leadership development programs are becoming popular in academic medicine as institutions seek solutions to problems. We developed and implemented a cohort-based leadership program within the Department of Foundational Medical Studies at our medical school in order to not only develop our next cadre of leaders but also to spread and disseminate the principles of leadership and enhance the recognition by all departmental members of the various leadership roles each holds.
\end{abstract}

Keywords Leadership training $\cdot$ Leadership capacity $\cdot$ Leader development $\cdot$ Academic leadership

\section{Introduction}

Leadership in academic medicine differs greatly from that in the corporate world. There exists simultaneously a rigidity of expected performance to produce an outcome that is relatively ubiquitous in terms of meeting societal demands and a flexibility to find unique methods for producing such an outcome. The hierarchical organization of the corporate world is replaced in academic medicine by a distributed model (Buller). As Buller describes, in a distributed organization power is shared among various groups, unlike in hierarchical organizations, where power is concentrated at the top. Such differences in structure and expectations have contributed to a less straightforward adoption and implementation of leadership training.

Leadership development in academic medicine provides a unique context as this sector lags behind others in leadership development, pressure exists between professional groups (i.e., administration and clinicians), and there are heavy constraints around time, technology, and finances [1]. The differences between the corporate world and academia are many and are at least in part why the endless books, papers, updates,

Douglas J. Gould

djgould@oakland.edu

1 Department of Foundational Medical Studies, Oakland University William Beaumont School of Medicine, Rochester, MI, USA

2 Department of Management and Marketing, School of Business Administration, Oakland University, Rochester, MI, USA workshops, conferences, and training sessions surrounding leadership have not been widely accepted, adopted, or embraced in the academic world. Despite strong calls for the use of evidence-based management in management practice equal to that used in medical decision-making [2], others have highlighted a surprising reluctance of health care organizations to take on evidence-based management in the same way as they have embraced evidence-based medicine [3].

Some medical education programs have recently addressed the need for incorporating leadership education in their curricula. In their work on clinical leadership, Swanwick and McKimm [4] stress the need for all clinical instructors to "be aware of the broad base of leadership attributes, knowledge, and skills that learners require" [p. 25]. Additionally, Bhatia et al. [5] present a curriculum for residents to gain administrative and leadership skills - in areas such as career development, conflict resolution, working with multidisciplinary teams, and effective communication. Mokshagundam et al. [6] highlight this need earlier in medical students' studies in pre-clinical phases. As leadership education becomes more of a priority in medical curricula, medical educators' own leadership education and continued leadership development becomes critical in the delivery of quality curricula and professional preparation.

Indeed, academia has much to gain from adopting at least some of the principles of leadership development practiced in the corporate world. An article in the Chronicle of Higher Education describes the benefits of "taking a cue from industry" in utilizing 360-degree reviews for the leadership development of academic administrators [7]. Leadership training programs 
can lead to $25 \%$ increase in participant learning, $28 \%$ increase in leadership behaviors performed on the job, and a $20 \%$ increase in overall job performance across a variety of industries and settings [8]. Leadership behaviors may include working with teams, articulating a vision, difficult conversations, negotiation, and even more pragmatic tasks such as developing a budgetall of which are desirable skills for a faculty member, yet skills that few possess, and even fewer have received formal and deliberate training in. Building from leadership development research and best practice, we developed and implemented a small, cohort-based leadership program within the Department of Foundational Medical Studies within our medical schoolLeadership Institute for Faculty Development (LIFD).

\section{LIFD Program}

\section{Description and Context}

The program is a cohort-based, yearlong endeavor designed to build on the school's community culture by fostering the development of leaders through self-awareness, leadership knowledge, and skills training and building collective leadership capacity. The overall program objectives were as follows:

1. Identify preferred leadership style(s) and characteristics, traits, and proclivities and apply those characteristics appropriately per situation;

2. Identify and assess the characteristics of high-functioning teams and the role a leader plays;

3. Demonstrate a growth mindset that fosters change and innovation;

4. Embrace positive leadership as a practice.
Our yearlong program consisted of a small (4 person) cohort of junior faculty members. The research was deemed exempt by our university's Institutional Review Board (IRBFY2021-131); however, we did contact all program participants to notify them of our intent to publish out of consideration. We decided to focus the first iteration of the program on junior-level, tenure-track faculty, assuming that senior faculty would have already sought out and experienced leadership training as they wished during their career - of note and as presented in the "Discussion" section, this assumption was not correct. A short narrative description of perceived benefits and a CV was required to apply for participation in the program. Applications were vetted by a small group of senior faculty members in the Department. The program included 360-degree feedback, coaching, skills training, and individual reflection, which were used to build individual human capital, whereas networking and action learning activities developed the collective leadership capacity within the participant cohort as recommended by Day [9]. Participants and the program lead (the Department Chair) met once per month, over lunch, in a building separate from the Department on campus. Both the lunch and location were chosen to give the program a "special" feel (i.e., not just another committee meeting). Monthly meetings were held between 11:00 and 1:00 on Fridays, the middle of the day was chosen to encourage participation from those with end-of-the-day family obligations.

See Table 1 for complete description of the sessions and program components.

\section{Program Framework}

Drawing from leadership theory and best practices, the program was built with three goals in mind: building participant self-

Table 1 Timeline and summary of program

\begin{tabular}{|c|c|c|c|c|}
\hline Month & $\begin{array}{l}\text { Goal } \\
\text { mapping }\end{array}$ & Session & Description & $\begin{array}{l}\text { Participant } \\
\text { ranking }\end{array}$ \\
\hline March & $1,2,3$ & Orientation & $\begin{array}{l}\text { Presentation of program goals, expected outcomes, } \\
\text { obligations, and timelines. Resources provided }\end{array}$ & $\mathrm{N} / \mathrm{A}$ \\
\hline April & $1,2,3$ & Multi-domain leadership workshop & 2-h workshop on multi-domain leadership & 3 \\
\hline April-May & 1 & 360-degree assessment and coaching & $\begin{array}{l}\text { Completion of custom } 360 \text { evaluation and 1-h debrief } \\
\text { (coaching and interpretation) }\end{array}$ & 4 \\
\hline April & $1,2,3$ & $\begin{array}{l}\text { Academic Impressions: Fundamentals of Leadership } \\
\text { in Higher Education, New Orleans, LA }\end{array}$ & $\begin{array}{l}\text { Skills training externship: building a team, supervision, } \\
\text { influencing others, difficult conversations }\end{array}$ & 2 \\
\hline Apr-Dec & 1 & Journaling activity & Reflective journaling & 5 \\
\hline June-July & 2,3 & The 9 Virtues of Exceptional Leaders book club & Book discussion & 1 \\
\hline June--Dec & 3 & Group project on communities of practice & $\begin{array}{l}\text { Cohort-led project to establish Communities of Practice at } \\
\text { school }\end{array}$ & 7 \\
\hline Aug-Oct & 2,3 & Harvard Business Review journal club & Journal clubs & 6 \\
\hline Nov & 2 & Budgeting & Budgeting basics presentation & 8 \\
\hline Dec & $\mathrm{N} / \mathrm{A}$ & Wrap-Up & Program assessment discussion & $\mathrm{N} / \mathrm{A}$ \\
\hline
\end{tabular}

a 1 = self-awareness, 2 = leader identity and competency development, 3 = collective leadership capacity 
awareness, developing leadership knowledge and skills, and building collective leadership capacity within the group. Specifically, we drew from the best practice recommendations presented in the meta-analysis of 335 studies of leadership training programs conducted by Lacerenza et al. [8]. These best practices and application within our program are summarized in Table 2.

As Swanwick and McKimm [4] note on clinical leadership, the "predominant emphasis ... is on the development of the individual, and this may be at odds with our increasing awareness of the emergent and relational nature of leadership" [p. 25], and we also strove to include elements fostering both individual and collective development. Day [9] distinguishes leader development, which builds individual self-awareness, self-confidence, and skills in individuals, from leadership development, which builds collective leadership capacity and interpersonal relationships through group-based activities. Most leadership development programs focus on leader development, offering training on identified skills such as problem-solving, strategic thinking, communication, adaptability, confidence, and technical skills. Leadership development initiatives are also necessary to promote interpersonal relationships required for successful organizational change, building commitment, trust, and positive workplace cultures [10]. A focus on leadership development or the collective leadership capacity helps individuals work more collegially and effectively with their peers, i.e., individuals with leadership training are better able to recognize, foster, and disseminate desired behaviors across a Department.
As both leadership development and leader development are deemed valuable and mutually supportive [9], our program was designed to address both individual (self-awareness and leadership competency) and collective development (collective leadership capacity). We describe each below.

\section{Self-awareness:}

Self-awareness is "an inwardly-focused evaluative process in which individuals make self/standard comparisons with the goal of better self-knowledge and improvement" [11]. Self-awareness was noted by medical leaders an important personal characteristic that enabled their leadership [12]. Likewise, self-awareness is a key driver of leadership development and awareness is especially important in adaption, transition, and changes [11]. We focused on two major ways to build participant self-awareness in the LIFD program: 360-degree feedback and consistent reflection.

360-degree feedback, or multi-rater feedback, capture individuals' self-assessments paired with perspectives of others such as managers, peers, and direct reports. Bracken et al. [13] define this type of feedback as 360 degrees. " $360^{\circ}$ Feedback is a process for collecting, quantifying, and reporting coworker observations about an individual (i.e., a ratee) that facilitates/enables three specific data-driven/based out-comes: (a) the collection of rater perceptions of the degree

Table 2 The application of leadership development best practice in LIFD

Best practice [7; p. 19]

"Resist the temptation to think that leaders cannot be trained; evidence suggests leadership training programs are effective."

"Conduct a needs analysis and identify the desired outcome(s) based on stakeholder goals before designing the program."

"Use multiple delivery methods when possible (e.g., information, demonstration, and practice) and if limitations prevent this, choose practice instead of other delivery methods"

"Use caution when spending additional resources on 360-degree feedback (evidence indicates that it might not be more effective than single-source feedback)."

"Provide multiple training sessions that are separated by time rather than a single, massed training session."

"Use caution when implementing self-administered training and instead, choose an internal or external trainer (evidence shows no differences in the effectiveness of internal and external trainers but indicates that self-administered training is less effective)."

"Consult with others outside of your field to ensure the program is both evidence-based and practically relevant (e.g., if you are a practitioner, collaborate with an academic)."

"Ensure the program is designed appropriately according to the desired outcome."
Implementation in LIFD

This idea was the basis of the program — we believe that faculty are leaders and can be developed.

A needs analysis was conducted through discussion with department chair and members of the Dean's team.

The program included multiple delivery methods (seminars, workshops, off-site conference, 1:1 coaching, participant-led presentations and sharing, and reflection).

We used a multi-domain 360-degree assessment that was based on validated leadership constructs and participants met $1: 1$ with a coach to make sense of the feedback and create developmental goals. Delivery and coaching was economical as it was delivered by university faculty members.

The program was designed to include multiple sessions over the course of 1 year.

The program included training components administered by both internal and external trainers.

The program was built in consultation with academics specializing in leadership development.

The program was built around 3 goals: building (1) self-awareness, (2) leadership knowledge and skill-building, and (3) building collective leadership capacity in the department. 
to which specific behaviors are exhibited; (b) the analysis of meaningful comparisons of rater perceptions across multiple ratees, between specific groups of raters for an individual ratee, and for ratee changes over time; and(c) the creation of sustainable individual, group, and/or organizational changes in behaviors valued by the organization" (p. 764). 360's are popular in development programs to provide an opportunity for a focal leader to build self-awareness, identify areas of developmental need, and set goals for improvement [14]. Because data is gathered from multiple sources, 360-degree assessments have a methodological advantage and meaningful data beyond other self-assessments [15]. 360-degree feedback tools are not measures of personality or individual differences (e.g., Meyers-Briggs Type Indicator) but rather present meaningful quantitative and qualitative feedback on number of identified competencies in an accessible format. 360-degree feedback is most effective when paired with and used only for developmental, not instrumental purposes. We introduced the 360-degree evaluation on day one of the program and two months in, each participant received an individualized hourlong debrief and discussion/consultation regarding the results from one of the authors of the manuscript.

Next, we focused on individual reflection throughout the program as an opportunity for participants to build their selfawareness. Evidence suggests that leadership identity and reflection support lifelong learning [16]. Integrating reflection in leadership development programs allows individuals to evaluate the significance of their experiences from a leadership perspective [17]. The process of reflective thinking is valuable for participants in a leadership development program who want to improve their ability to lead others and enable them to gain insight into the complexities of situations [17]. As suggested by research, participants were provided a journal at the start of the program and encouraged to document experiences. The importance of deep reflective practice was provided in the early sessions and reinforced throughout the program. Reflective practice may result in a deeper approach to learning, improvement in reasoning of complex cases, and enhancement in professional identity and professionalism [16].

\section{Leader Identity and Competency Development}

Most leadership development programs focus on building leadership competency within participants [18] based on a certain theory (transformational, servant, etc.) or competency framework deemed important within an organization. Rather than drawing on one specific competency framework, we took a multi-domain, identity-based approach [19], in which leader competency is developed more personally. This approach highlights that leader identity is the process through which leader competence breadth and depth are built and is more akin to aa character-perspective. Building a leader's sense of self as a leader is critical in facilitating lifelong engagement in development [20] and is "at the heart of our understanding of leadership dynamics" [21; p. 124]. As leader identity cuts across all life domains (work, personal community, etc.), we also welcomed discussion beyond the workplace [19].

Throughout the program, attention was given to unpacking leadership expectations and assumptions, an understanding of what leadership means, and building individual identities as leaders. This was important as the meaning of leadership is a foundation of one's sense of self as a leader [19]. Relevant theories, such as leader identity theory and implicit leadership theories, were discussed, especially in the multi-domain leadership session early in the program. Implicit theories of leadership suggest that group members have often unspoken expectations and assumptions about the characteristics, behaviors, and qualities they deem to be inherent in a leader. These assumptions shape an individual's perceptions and responses to leaders as well as participants own implicit theories shape the extent to which they see themselves as leaders. Schyns et al. [22] note "combining leader and leadership development by raising self-and social-awareness of implicit leadership theories can facilitate the development of leader identities and ultimately ease the process of negotiating leadership more constructively and effectively, and hopefully with less conflict" (p. 406).

Although the primary goal of the multi-domain 360-degree feedback assessment tool was to build self-awareness, the 360 also served to highlight specific leader competencies in which participants might benefit most from additional resources, in work, personal, and community domains. The assessment included validated measures of positive leader behaviors in the areas of transformational and transactional leadership, including acting as a role model, building a vision, encouraging a team approach, setting high-expectations, creative thinking, and problem-solving, providing individualized consideration and delivering positive feedback [23] as well as cognitive- and emotion-based trust [24]. The 360 was also used as a teaching tool to highlight important leader behaviors with specific feedback on strengths and weaknesses in these areas. Additional resources, such as articles, websites, and podcasts, were provided to each leader on areas highlighted within the coaching meeting and follow-up communication. Specific behavioral intentions were decided upon within the coaching meetings as well, to practice identified behaviors and skills. The 360 also included a measure of implicit theories of leadership [21], which provided feedback not on the focal leader's behavior, but rather on the prototypes and expectation of leaders that raters held more generally. This information was particularly useful for participants to gain an understanding of the perspectives and expectations that various stakeholders held of leaders more generally. Additionally, workshops on specialized skills were included around topics specific to the organizational context such as budgeting. 
Table 3 Narrative responses

\begin{tabular}{|c|c|}
\hline Open-ended question & Narrative response themes \\
\hline $\begin{array}{l}\text { Describe what you have learned from your participation in the LIFD } \\
\text { program? }\end{array}$ & $\begin{array}{l}\text { Different leadership styles and virtues associated with leadership } \\
\text { Personal leadership traits and qualities and how they intersect }\end{array}$ \\
\hline $\begin{array}{l}\text { In what ways have you applied what you have learned from } \\
\text { participation in the LIFD program? }\end{array}$ & $\begin{array}{l}\text { Work to apply lessons learned from the program in multiple settings and } \\
\text { situations (including outside of work) } \\
\text { Intend to seek more leadership training }\end{array}$ \\
\hline In what ways has participation in the LIFD program benefitted you? & $\begin{array}{l}\text { Build confidence } \\
\text { Find balance across work-community-family spectrum }\end{array}$ \\
\hline $\begin{array}{l}\text { How has participation in the LIFD program changed your view of } \\
\text { FMS, OUWB, or OU? }\end{array}$ & $\begin{array}{l}\text { Better recognition of school's impact and potential } \\
\text { Showed that current leadership cares }\end{array}$ \\
\hline $\begin{array}{l}\text { How have your goals evolved from those outlined in your LIFD } \\
\text { program application until now? }\end{array}$ & $\begin{array}{l}\text { Recognition that skills development is not the most important part of leadership } \\
\text { Appreciate the weight of high levels of responsibility more deeply }\end{array}$ \\
\hline $\begin{array}{l}\text { Please list and describe any suggestions you might have for the next } \\
\text { iteration of the LIFD program. }\end{array}$ & $\begin{array}{l}\text { Deeper discussions about issues at our school } \\
\text { Increase number of participants }\end{array}$ \\
\hline
\end{tabular}

Finally, participants read about and applied a virtue-based approach to leadership growth. Mid-way through the program, leaders participated in a book-club style discussion of The 9 Virtues of Exceptional Leaders [25] to facilitate participants leader identity and competence development through discussing and practicing virtue. As described in the book, virtue "is not an approach to management - or even to leadership.... Rather virtue is a way of living, developed over a lifetime" (p. 6). The book club discussion and associated exercises helped to foster participants deeper-level characteristics and the behaviors that manifest from them.

\section{Collective Leadership Capacity}

Whereas self-awareness and leadership competency development focus on individual leader development, building collective capacity within a unit addresses leadership developmental needs [8]. Although developing individuals is important, building collective leadership capacity within a department is often overlooked, yet critical as organizations face increasingly complex environments and impacts, such as COVID-19, which necessitate a faster pace of change. Collective leadership is defined as "multiple individuals assuming (and perhaps divesting themselves) of leadership roles over time in both formal and informal relationships" [18; p. 1]. The increase in individuals with substantive leadership training provided a safety net and a reserve of faculty members capable of navigating rapid change and uncertainty.

Our leadership cohort was developed loosely on Wenger's theory of communities of practice [26]. Communities of practice are "groups of people who share a concern or a passion for something they do and learn how to do it better as they interact regularly" [25] The cohort as a community of practice served to create a space for learning together, sharing ideas, grow in confidence, and improve coordination and communication. Although for practical considerations (e.g., financial and control of outcomes), we chose to start with an intradepartmental program, and cohorts are expected to bridge the gap between departments within organizations by bringing leaders from each area together to work toward common goals [27]; with this in mind, we may seek to expand the cohort size in future iterations. Cohorts are expected to increase dialogue, enhance performance, and improve peer and team relationships [27]. Utilizing the cohort approach in a leadership development program will hopefully improve performance among the group [27].

Additionally, collective leadership capacity was built through communication and relationship building of participants to others within the school and university atlarge. Of special note, around the time the LIFD program began, our school had a change in Dean. The new Dean took an interest in LIFD and we were fortunate enough to have him attend half of the sessions (book club, journal club, introduction, group project planning/discussion). Program evaluation indicated that participants felt that the attendance of the Dean was a program highlight, they learned a lot from him, and it added a level of legitimacy to the program.

\section{Program Evaluation}

At the end of the program, a 10-item Qualtrics survey was distributed to participants. All participants completed the evaluation survey. Participants were asked to rank the program sessions (\#1 best to \#8 least useful). It should be noted that although there were ten total sessions, the first session was an introduction and the last was a wrap-up; therefore, rankings ranged 1-8 (see participant ranking in Table 1). Additionally, participants were asked to respond to 6 narrative items centered around their experience, learning, application, and ideas for improvement (see Table 3 for a summary). Additionally, 
Table 4 Satisfaction assessment

\begin{tabular}{ll}
\hline Evaluation criteria & Mean evaluation \\
\hline Encourage others to participate & 10 \\
Lunch & 9.75 \\
Session length & 9.75 \\
Program leadership & 9.75 \\
Dean participation & 9.75 \\
Instructors & 9.75 \\
Session location & 9.25 \\
Participant engagement & 9.25 \\
Program length & 9.25 \\
Met objectives & 9 \\
Worthiness & 8.8 \\
Composition of the cohort & 8.5 \\
Organization & 8.4 \\
\hline
\end{tabular}

participants indicated their satisfaction with various aspects of the program (see Table 4) on a ten-item Likert scale using a slide bar. A final open-ended comment box was provided for feedback on any of the above items.

\section{Future Directions}

Based on user feedback, we planned several changes to the next iteration of LIFD, including moving the budgeting session earlier in the curriculum, putting more structure around the book and journal club activities, and allowing more structured time for the group project. Unfortunately, just as the program was to start for the 2020-2021 year, COVID-19 forced us to work from home and so the program has been delayed for one year.

\section{Conclusions}

Medical school faculties benefit from leadership training, and such training provides faculty members with critical leadership skills and allows for identification of individual traits and interests that benefit the department and school as a whole. Further, programs that build collective leadership capacity increase Departmental resilience and the ability to react to changing situation. Learning how to interact effectively with peers is "baked in" to such training, allowing for a more collaborative scholarly environment. Small, intradepartmental leadership programs not only provide Departments with future committee chairs and course directors but also provide for growth of the individual and foster a positive work environment.

Data Availability N/A.

\section{Compliance with Ethical Standards}

Conflict of Interest The authors declare that they have no conflict of interest.

Code Availability N/A.

\section{References}

1. McAlearney AS. Leadership development in healthcare: a qualitative study. J Organ Behav. 2006;27:967-82.

2. Reay T, Berta W, Kohn MK. What's the evidence on evidencebased management. Acad Manag Perspect. 2017;23(4). https://doi. org/10.5465/amp.23.4.5.

3. Kovner AR, Rundall TG. Evidence-based management reconsidered. Front Health Serv Manag. 2006;22(3):3-22.

4. Swanwick T, McKimm J. What is clinical leadership....and why is it important? Clin Teach. 2011;8(1):22-6.

5. Bhatia K, Takayesu JK, Arbelaez CA, Peak DA, Nadel ES. Resident interest academies: academic and leadership skills development. Med Sci Educ. 2015;25:215-6.

6. Mokshagundam S, Pitkin J, Dekhtyar M, Santen S, Hammoud M, Skochelak SE. Engaging medical students in leadership development. Med Sci Educ. 2015;29:849-53.

7. Tugend A. To improve leadership, some colleges take a cue from industry: 360-degree reviews. Chron High Ed. 2019.

8. Lacerenza CN, Reyes DL, Marlow SL, Joseph DL, Salas E. Leadership training design, delivery, and implementation: a metaanalysis. J App Psych. 2017;102(12):1686-718.

9. Day DV. Leadership development: a review in context. Leadersh Q. 2000;11(4):581-613.

10. McCallum S, O'Connell D. Social capital and leadership development: building stronger leadership through enhanced relational skills. Leadersh Org Dev J. 2009;30(2):152-66.

11. Ashley GC, Reiter-Palmon R. Self-awareness and the evolution of leaders: the need for a better measure of self-awareness. J Behav Appl Manag. 2012;14(1):2-17.

12. Arnold L, Cuddy P, Hathaway SB, Quaintance JL, Kanter SL. Medical leaders identify personal characteristics and experiences that contribute to leadership success in medicine. MedEdPublish. 2019. https://doi.org/10.15694/mep.2019.000206.1.

13. Bracken DW, Rose DS, Church AH. The evolution and devolution of $360^{\circ}$ feedback. Ind Organ Psychol. 2016;9(4):761-94.

14. Bailey C, Austin M. Outcomes: the role of feedback characteristics, self-efficacy and importance of feedback dimensions to focal managers' current role. Int J Sel Assess. 2006;14(1):51-66.

15. Solansky ST. The evaluation of two key leadership development program components: leadership skills assessment and leadership mentoring. Leadersh Q. 2010;21(4):675-81.

16. Alizadeh M, Mirzazadeh A, Parmelee DX, Peyton E, Mehrdad N, Janani L, et al. Leadership identity development through reflection and feedback in team-based learning medical student teams. Teach Learn Med. 2018;30(1):76-83.

17. Densten IL, Gray JH. Leadership development and reflection: what is the connection? Int J Educ Manag. 2001;15(3):119-24.

18. Eva N, Cox JW, Herman HM, Lowe KB. From competency to conversation: a multi-perspective approach to collective leadership development. Leadersh Q. 2019;101346.

19. Hammond M, Clapp-Smith R, Palanski M. Beyond (just) the workplace: a theory of leader development across multiple domains. Acad Manag Rev. 2017;42(3):481-98. 
20. Day DV, Harrison MM, Halpin SM. An integrative approach to leader development: connecting adult development, identity, and expertise. Mahwah: Routledge; 2009.

21. Epitropaki O, Kark R, Mainemelis C, Lord RG. Leadership and followership identity processes: a multilevel review. Leadersh Q. 2017;28:104-29.

22. Schyns B, Kiefer T, Kerschreiter R, Tymon A. Teaching implicit leadership theories to develop leaders and leadership: how and why it can make a difference. Acad Manag Learn Ed. 2011;10(3):397408.

23. Podsakoff PM, MacKenzie SB, Moorman RH, Fetter R. Transformational leader behaviors and their effects on followers' trust in leader, satisfaction, and organizational citizenship behaviors. Leadersh Q. 1990;1(2):107-42.
24. Yang J, Mossholder KW. Examining the effects of trust in leaders: a bases-and-foci approach. Leadersh Q. 2010;2010:50-63.

25. Haden KN, Jenkins R. The 9 virtues of exceptional leaders: unlocking your leadership potential. Atlanta: Deeds Publishing; 2015.

26. Wenger-Trayner, E. and Wenger-Trayner, B. Communities of practice: a brief introduction. 2015 .

27. Sharlow J, Langenhoff P, Bhatti A, Spiers J, Cummings G. Learning together: a cohort approach to organizational leadership development. Leadersh Health Serv. 2009;22(4):317-28.

Publisher's Note Springer Nature remains neutral with regard to jurisdictional claims in published maps and institutional affiliations. 